\section{Ecotoxicological Impact of the Bioherbicide Leptospermone on the Microbial Community of Two Arable Soils}

\author{
Sana Romdhane ${ }^{1,2,3}$, Marion Devers-Lamrani ${ }^{3}$, Lise Barthelmebs ${ }^{1 *}$, \\ Christophe Calvayrac ${ }^{1}$, Cédric Bertrand ${ }^{2}$, Jean-François Cooper ${ }^{2}$, Franck E. Dayan ${ }^{4}$ and \\ Fabrice Martin-Laurent ${ }^{3}$
}

${ }^{1}$ Biocapteurs Analyse Environnement, EA 4218, University of Perpignan via Domitia, Perpignan, France, ${ }^{2}$ Centre de Recherches Insulaires et Observatoire de l'Environnement, USR 3278 EPHE-Centre National de la Recherche Scientifique, University of Perpignan via Domitia, Perpignan, France, ${ }^{3}$ Institut National de la Recherche Agronomique, UMR 1347 Agroécologie, EcolDur, Dijon, France, ${ }^{4}$ Bioagricultural Sciences and Pest Management Department, Colorado State University, Fort Collins, CO, USA

The ecotoxicological impact of leptospermone, a $\beta$-triketone bioherbicide, on the bacterial community of two arable soils was investigated. Soil microcosms were exposed to $0 \times$ (control), $1 \times$ or $10 \times$ recommended dose of leptospermone. The $\beta$-triketone was moderately adsorbed to both soils (i.e.,: $K_{\mathrm{fa}} \sim 1.2$ and $K_{\mathrm{oc}} \sim 140 \mathrm{~mL} \mathrm{~g}^{-1}$ ). Its dissipation was lower in sterilized than in unsterilized soils suggesting that it was mainly influenced by biotic factors. Within 45 days, leptospermone disappeared almost entirely from one of the two soils (i.e., $\mathrm{DT}_{50}<10$ days), while $25 \%$ remained in the other. The composition of the microbial community assessed by qPCR targeting 11 microbial groups was found to be significantly modified in soil microcosms exposed to leptospermone. Pyrosequencing of $16 \mathrm{~S}$ rRNA gene amplicons showed a shift in the bacterial community structure and a significant impact of leptospermone on the diversity of the soil bacterial community. Changes in the composition, and in the $\alpha$ - and $\beta$-diversity of microbial community were transient in the soil able to fully dissipate the leptospermone, but were persistent in the soil where $\beta$-triketone remained. To conclude the bacterial community of the two soils was sensitive to leptospermone and its resilience was observed only when leptospermone was fully dissipated.

Keywords: bacterial community, microbial ecotoxicology, biodegradation, bioherbicide, leptospermone

\section{INTRODUCTION}

Agriculture is facing critical challenges to ensure high crop production and quality, while preserving environmental and human health (Brussaard et al., 2010). Among pressures exerted by agriculture on the environment, synthetic plant protection products (PPPs) are of concern because they can persist in arable soils and be transferred to different compartments of the environment where they are frequently detected (Margni et al., 2002; Polyrakis, 2009). In this context, the use of natural active compounds, also known as biopesticides, may be an interesting alternative for crop protection as they are considered to be less harmful and environmentally safer (Dewhurst, 2001; Dayan et al., 2009, 2011; Cantrell et al., 2012; Seiber et al., 2014). Within the last few years, several studies highlighted the effectiveness of biopesticides for the control of different pests in various crops (Copping and Menn, 2000). Due to the diversity of biopesticide modes of action, 
risks of resistance emergence is considerably reduced (Copping and Menn, 2000; Dayan and Duke, 2014). Consequently, the biopesticide market has been gaining greater approval and interest for pest management (Copping and Menn, 2000; Cantrell et al., 2012; Seiber et al., 2014).

Despite this enthusiasm for natural alternatives, few bioherbicides are commercially available; among them manuka oil is being considered as a pre- and post-emergence herbicide to control several broadleaf and grass weeds at a rate of $3 \mathrm{~L} \mathrm{ha}^{-1}$ (Dayan et al., 2011). The active ingredient in the essential oil of Manuka tree (Leptospermum scoparium) is the $\beta$-triketone leptospermone [2,2,4,4-tetramethyl-6-(3-methyl-1-oxobutyl)1,3,5-cyclohexanetrione (Hellyer, 1968; Dayan et al., 2007, 2011). This natural herbicide is also produced by other species such as the allopathic plant bottlebrush plant (Callistemon citrinus) (Gray et al., 1980; Mitchell et al., 2001). Leptospermone targets 4-hydroxyphenylpyruvate dioxygenase (HPPD), a key enzyme in plant carotenoid biosynthesis, that catalyzes the conversion of 4-hydroxyphenylpyruvate into homogentisate leading to foliage bleaching of treated weeds (Schulz et al., 1993; Meazza et al., 2002; Dayan et al., 2007, 2011). HPPD is also the target site for commercial synthetic $\beta$-triketones herbicides (e.g., sulcotrione, mesotrione, and tembotrione), which were derived from the structural backbone of leptospermone (Gray et al., 1980; Schulz et al., 1993; Lee et al., 2008). HPPD is expressed by many organisms, including plants (Moran, 2005), and several bacteria (Lee et al., 2008), that could be indirectly affected by this family of herbicides. Indeed, this bioherbicide also has antimicrobial, antiviral, and acaricidal activities (Jeong et al., 2009a,b).

To date there are only few studies describing the environmental fate and ecotoxicological impact of biopesticides on non-target organisms (NTO). In spite of their natural origin, biopesticides are active compounds used to eradicate target organisms in crops. Like other agrochemicals, once released in the soil, they may undergo a range of abiotic and biotic processes (i.e., sorption, degradation, and transport) modulating their environmental fate and conditioning their side effects on NTO. For example, azadirachtin, an natural insecticide from neem (Azadirachta indica), exerts adverse effect on soil microbial community (Gopal et al., 2007; Gupta et al., 2013; Singh et al., 2015a,b). These reports underscored the need to assess the environmental fate and ecotoxicological impact of biopesticides on NTO. Among NTOs, the European Food Safety Authorithy (EFSA) proposed soil microorganisms, which support numerous functions (Whitman et al., 1998; Nannipieri et al., 2003; Philippot et al., 2012) contributing to regulation and maintenance of soil ecosystemic services, as specific protection goals (SPGs) for environmental risk assessment of PPPs (EFSA, 2010; Science for Environment Policy, 2015). Consequently, the ecotoxicological impact of PPPs on soil microorganisms will have to be assessed to fulfill the SPGs. Within this context, innovative tools relying on high throughput soil DNA analyses give new insight for assessing ecotoxicological impact of PPPs on soil microbial community (Martin-Laurent et al., 2013; Cai et al., 2015; Wang et al., 2015).

Although leptospermone is considered as a selective and efficient bioherbicide candidate for crop protection (Dayan et al., 2009, 2011; Cantrell et al., 2012), only few studies have examined its environmental fate. It has a relatively short half-life in water and is rapidly dissipated via photodegradation (Trivella et al., 2015). However, there is no report on abiotic and biotic processes contributing to leptospermone dissipation. Likewise its ecotoxicological impact on soil microbial community has not been assessed although a vast majority of microorganisms harbor $h p p d$ gene, and could therefore be potentially sensitive to leptospermone. To tackle these questions, this work reports a microcosm study designed to describe the fate of leptospermone and its ecotoxicological impact on the composition and the diversity of the soil microbial community. Two agricultural soils with contrasted physicochemical properties were selected as model environments. Leptospermone was applied at $1 \times$, or $10 \times$ recommended agronomical rate on soil microcosms along with an untreated control. The scenario of exposure of the microbial community to leptospermone was estimated by monitoring its dissipation in soil microcosms. The ecotoxicological impact of leptospermone on the soil bacterial composition and diversity was investigated from DNA samples, extracted directly from soils, by means of real-time quantitative PCR targeting eleven microbial groups and pyrosequencing of $16 \mathrm{~S}$ rRNA gene amplicons, respectively.

\section{MATERIALS AND METHODS}

\section{Soil Sampling and Characteristics}

Soil samples were collected from the surface layer $(0-20 \mathrm{~cm})$ of two different arable field sites [Perpignan (P) and Saint Jean de Fos (SJF), France] selected according to their physicochemical properties. $\mathrm{P}$ soil is an experimental field site having a $\beta$ triketone history treatment (Calvayrac et al., 2012) and SJF soil was neither cultivated nor treated with pesticides for the last 5 years. Soil samples were sieved to $2 \mathrm{~mm}$ and soil moisture was measured. Soils were stored at $4{ }^{\circ} \mathrm{C}$ until use. The composition and characteristics of the P soil was $13.9 \%$ clay, $60.5 \%$ silt, $25.6 \%$ sand, $20 \%$ soil humidity, $1.7 \%$ organic matter, $0.98 \%$ organic carbon, 15.5 meq $100 \mathrm{~g}^{-1}$ cation exchange capacity (CEC), $214 \% \mathrm{Ca}^{2+} / \mathrm{CEC}$, and $\mathrm{pH}$ in water 8.1 . The composition and characteristics of the SJF soil was $25.8 \%$ clay, $27.3 \%$ silt, $46.9 \%$ sand, $15 \%$ soil humidity, $1.5 \%$ organic matter, $0.9 \%$ organic carbon, 10.4 meq $100 \mathrm{~g}^{-1}$ cation exchange capacity (CEC), 98\% $\mathrm{Ca}^{2+} / \mathrm{CEC}$, and $\mathrm{pH}$ in water 7.62 .

\section{Microcosm Set Up}

Pure leptospermone was synthesized as described by Owens et al. (2013). Soil samples (20 g) were treated with a leptospermone solution prepared in methanol at $0 \times(\mathrm{D} 0$, control), $1 \times(\mathrm{D} 1$, $\left.5 \mu \mathrm{g} \mathrm{g}^{-1}\right)$, and $10 \times\left(\mathrm{D} 10,50 \mu \mathrm{g} \mathrm{g}^{-1}\right)$ recommended field dose. Methanol was then evaporated and the microcosms were moistened to reach $33 \%$ of soil water-holding capacity and incubated in the dark for 45 days at $22^{\circ} \mathrm{C}$. The abiotic degradation of leptospermone in the microcosms was assessed in soils sterilized using $\gamma$-radiation. Soil samples were analyzed at $0,2,4$, $8,15,30$, and 45 days after the treatment $(d)$. Soil microcosms were prepared in triplicates for each soil, treatment and time points $\left(n_{\text {tot }}=252\right)$. 


\section{Fate of Leptospermone in Soil Microcosms Kinetics of Dissipation}

During the time course of the incubation, the dissipation of leptospermone was measured. At each sampling time, $\mathrm{P}$ and SJF soil samples $(10 \mathrm{~g})$ were acidified by $3 \mathrm{~mL}$ of $0.1 \mathrm{M}$ hydrochloric acid solution and homogenized by vortex mixing, then extracted twice with $30 \mathrm{~mL}$ of ethyl acetate for $60 \mathrm{~min}$. Organic phases were filtered on a Whatman filter GF/A and evaporated to dryness at $30^{\circ} \mathrm{C}$. Dry extracts were eluted with methanol $(5 \mathrm{~mL})$. The final extract was analyzed by highperformance liquid chromatography (HPLC) Jasco apparatus equipped with a Phenomenex Luna C18 column $(150 \times 3.0 \mathrm{~mm}$; $5 \mu \mathrm{m})$ and a diode array detector Jasco $875-\mathrm{UV}$ set. The mobile phase consisted of a mixture of water (A) and acetonitrile (B) both acidified by $0.1 \%$ formic acid and delivered at a flow rate of $0.5 \mathrm{~mL} \mathrm{~min}{ }^{-1}$. The gradient method was: for $3 \mathrm{~min} 95 \%$ (A-5\% (B), from 3 to $15 \min 5 \%(A)-95 \%$ (B) maintained for $7 \mathrm{~min}$, then back to $95 \%$ (A) $-5 \%$ (B) from 22 to 26 min. No chromatographic interference was detected. Detection was carried out by using UV light (wavelength, $280 \mathrm{~nm}$ ). The quantification limit of the analysis method was estimated at $0.2 \mathrm{mg} \mathrm{L}^{-1}$. Calibration curves were established using blank soil samples prepared according to the above procedures and spiked with a concentration range of leptospermone from 0.5 to 50 $\mu \mathrm{g} \mathrm{g}^{-1}$. The obtained curves $\left(R^{2}=0.99, n=3\right)$ were used to determine concentrations of remaining leptospermone in soil extracts.

\section{Adsorption Isotherms}

Adsorption isotherms of leptospermone to $\mathrm{P}$ and SJF soils were measured by batch equilibrium method (Wilson and Foy, 1992; OECD, 2000; Cherrier et al., 2004). In order to determine the time required to reach the equilibrium, $5 \mathrm{~mL}$ of leptospermone at $20 \mathrm{mg} \mathrm{L}^{-1}$ prepared in $0.01 \mathrm{M} \mathrm{CaCl}_{2}$ solution were added to $1 \mathrm{~g}$ of each soil, placed on a vertical shaker and agitated for $0.5,1,2,3,4$, 8 , and $24 \mathrm{~h}$. Soil suspensions were centrifuged at $3500 \times \mathrm{g}$ for 10 $\min$. The supernatants were recovered and the $\mathrm{pH}$ was adjusted to $\mathrm{pH} 9$ with $1 \mathrm{M}$ Tris buffer. Leptospermone remaining in supernatants was analyzed by HPLC/UV. Adsorption isotherms were obtained from HPLC analysis of soil samples spiked with a range of leptospermone solutions prepared at different concentrations $\left(1,2,5,10,20\right.$, and $\left.40 \mathrm{mg} \mathrm{L}^{-1}\right)$ and agitated for three $\mathrm{h}$ following the protocol described above.

\section{Ecotoxicological Impact of Leptospermone on Soil Bacterial Community Direct Soil DNA Extraction}

DNA was extracted from $1 \mathrm{~g}$ of each soil sample according to the ISO 11063 standard derived from Martin-Laurent et al. (2001). Briefly, samples were mixed with $4 \mathrm{~mL}$ of extraction buffer containing $100 \mathrm{mM}$ EDTA, $100 \mathrm{mM}$ Tris ( $\mathrm{pH} \mathrm{8.0),} 100$ $\mathrm{mM} \mathrm{NaCl}, 1 \%(\mathrm{w} / \mathrm{v})$ polyvinylpyrrolidone, and $2 \%(\mathrm{w} / \mathrm{v})$ sodium dodecyl sulfate in a $5 \mathrm{~mL}$ mini-bead-beater tube containing $2 \mathrm{~g}$ of $106-\mu \mathrm{m}$-diameter glass beads and 8 glass beads of $2-\mathrm{mm}$ diameter. Samples were then homogenized for $30 \mathrm{~s}$ at $1600 \mathrm{rpm}$ in a mini-bead beater cell disrupter (Mikro-Dismembrator ${ }^{\odot}$, Sartorius AG, Germany). After an incubation of $15 \mathrm{~min}$ at $70^{\circ} \mathrm{C}$, soil components were eliminated by centrifugation at $14000 \times \mathrm{g}$ for $1 \mathrm{~min}$ at $4^{\circ} \mathrm{C}$. Proteins were then precipitated with sodium acetate at a final concentration of $0.3 \mathrm{M}$. After centrifugation at $14000 \times \mathrm{g}$ for $10 \mathrm{~min}$, supernatants were recovered and nucleic acids were precipitated with ice-cold isopropanol and washed with $70 \%$ ethanol. DNA was purified using a Sepharose 4B spin, polyvinylpyrrolidone (PVPP) spin columns and NucleoSpin ${ }^{\circledR}$ kits (Machery-Nagel, Germany). DNA concentration was quantified using the Quant-iT ${ }^{\mathrm{TM}}$ PicoGreen ${ }^{\circledR}$ dsDNA Assay Kit (Invitrogen ${ }^{\mathrm{TM}}$, France) following the manufacturer's instructions. The absence of PCR inhibitors in DNA extracts was verified according to Henry et al. (2006). No inhibition was detected in $2 \mu \mathrm{L}$ soil DNA template diluted at 0.1 ng $\mu \mathrm{L}^{-1}$.

\section{Abundance of Total Bacteria and Phylum-Specific Groups}

The abundances of total bacteria, several bacterial taxa and Crenarchaeota were measured in P and SJF soils treated (D1, D10) or not (D0) with leptospermone after $0,2,4,8,15$, 30 , and 45 days of incubation by real-time quantitative PCR (qPCR) targeting 16S rRNA gene sequences according to ISO/DIS 17601 standard as previously described (Petric et al., 2011). Eleven taxa-specific primers (Supplementary Table 1) were used to quantify $\alpha$-Proteobacteria, $\beta$-Proteobacteria, $\gamma$ Proteobacteria, Acidobacteria, Actinobacteria, Verrucomicrobia, Bacteroidetes, Firmicutes, Gemmatimonadetes, Planctomycetes, and Crenarchaeota (Muyzer et al., 1993; Ochsenreiter et al., 2003; Fierer et al., 2005; Muhling et al., 2008; Philippot et al., 2009). qPCR assays were carried out in an ABI 7900 HT Real-time PCR System (Applied Biosystems, USA) in a final reaction mixture of $15 \mu \mathrm{L}$ containing SYBR green PCR Master Mix (Absolute ${ }^{\mathrm{TM}}$ SYBR ${ }^{\circledR}$ Green Rox Abgene, Thermo Fisher Scientific, France), 250 ng of T4 gp32 (Qbiogene, MP Biomedicals, France), $1 \mathrm{mM}$ of each primer and $0.2 \mathrm{ng}$ of soil DNA template. qPCR runs were as follows: denaturation step for $15 \mathrm{~min}$ at $95^{\circ} \mathrm{C}$, then 35 cycles of $15 \mathrm{~s}$ of denaturation at $95^{\circ} \mathrm{C}, 30 \mathrm{~s}$ of annealing at the optimal temperature for primer annealing, elongation for $30 \mathrm{~s}$ at $72^{\circ} \mathrm{C}, 30 \mathrm{~s}$ for data acquisition at $80^{\circ} \mathrm{C}$, and a melting curve stage with $15 \mathrm{~s}$ at $95^{\circ} \mathrm{C}, 15 \mathrm{~s}$ at $78^{\circ} \mathrm{C}$, and $15 \mathrm{~s}$ at $95^{\circ} \mathrm{C}$. Standard curves were generated using serial dilutions of linearized plasmid pGEM-T containing each standard gene sequence (ranging from $10^{7}$ to $10^{2}$ copies per qPCR reaction). For each qPCR assay, qPCR calibration is performed in triplicate and three no-template controls (NTC) were also included.

\section{Diversity of the Bacterial Community}

The diversity of the bacterial community was measured for P and SJF soils treated (D1 or D10) or not with leptospermone for 4 and 45 days. Diversity was monitored by 454 pyrosequencing of the V4 ultravariable region of $16 \mathrm{~S}$ rRNA gene using 515F (5- GTGCCAGCMGCCGCGGTAA- 3) and 806R (5GGACTACHVGGGTWTCTAAT-3) primer pair (Turner et al., 1999; Liu et al., 2007; Caporaso et al., 2011). A two-step PCR procedure was used to amplify $16 \mathrm{~S}$ rRNA gene from obtained DNA extracts as described by Berry et al. (2012). In the first step of this protocol, 20 cycles of amplification were performed 
in triplicate using the $515 \mathrm{~F}-806 \mathrm{R}$ primer pair. Triplicates of each PCR reaction were pooled to a one PCR product. Then, $1 \mu \mathrm{L}$ of these $16 \mathrm{~S}$ rRNA amplicons was used as template to carry out 15 cycles of amplification with barcoded primers. The size of the amplicons was verified by electrophoresis performed on a $1.5 \%$ agarose gel. 16S rRNA amplicons were pooled and purified using the QIAEX II kit (Qiagen, France). Each sample was quantified using the Quant-iT ${ }^{\mathrm{TM}}$ PicoGreen ${ }^{\circledR}$ dsDNA Assay Kit (Invitrogen, France). Pooled samples were sequenced on a 454 FLX Genome Sequencer (Roche) by Genoscreen (Lille, France) using the Titanium Chemistry. Sequence data analysis was performed using QIIME (Quantitative Insights into Microbial Ecology) version 1.8.0 (Caporaso et al., 2010b). After splitting the libraries, 16S rRNA sequences were denoised, chimera were removed and Operational Taxonomic Units (OTUs) were selected at 97\% similarity using UPARSE (Edgar, 2010). Representative 16S rRNA sequences for each OTU were aligned using Pynast (Caporaso et al., 2010a) and their taxonomy was assigned by comparison with the GreenGenes database (http://www.ncbi.nlm.nih.gov/genbank/) using uclust algorithm (Edgar, 2010). Maximum likelihood phylogeny was calculated using FastTree 2 algorithm (Price et al., 2010). Phylogenetic tree plotting with additional OTU abundance data was performed using the Interactive Tree of Life (iTOL) webserver (Letunic and Bork, 2007). Two hundred and fifty OTUs representing $65 \%$ of the total number of sequences are represented on this phylogenetic tree. For each treatment, the average abundance of each OTU was calculated among replicates. Several $\alpha$ diversity indices were calculated using the rarefied OTU table at the depth of 1900 sequences per sample (PD whole tree, Chao 1, Dominance, Simpson, and Shannon indices). Principal Coordinate Analysis (PCoA) plots were generated in QIIME based on weighted UniFrac distance matrix and coordinates were used to draw 3D figures. Sequences were deposited in GenBank to the sequence read archive (SRA) under the accession number SRP061834.

\section{Statistical Analysis}

Data were subjected to statistical analysis of variance with a significance threshold set at a $p$-value of 0.05 using $\mathrm{R}$ software ( $\mathrm{R}$ foundation for statistical computing, Austria). For qPCR results, abundances of specific taxa were log-transformed and subjected to an analysis of variance (ANOVA). The homogeneity of variances was verified and Tukey's test was performed for each treatment and each time point. Not all qPCR data showed a normal distribution (16S rRNA, $\alpha$-Proteobacteria, $\beta$ Proteobacteria, $\gamma$-Proteobacteria, Bacteroidetes, Firmicutes, and Crenarchaeota). Consequently, non-parametric test (KruskalWallis test and Mann-Whitney U) was carried out on nonnormal distributed data and diversity indices to determine differences between treatments. To detect significant differences among treatments and time, a PERMANOVA analysis was carried out on the distance matrix for principal coordinate analysis (PCoA) using the ADONIS function from $\mathrm{R}$ package "vegan" (Oksanen et al., 2011). Groups affected by leptospermone treatment were detected by the nearest shrunken centroid approach using the "pamr" package under R (Tibshirani et al., 2002).

\section{RESULTS}

\section{Fate of Leptospermone in Soil Microcosms}

The soil behavior of leptospermone was evaluated with adsorption isotherms in $\mathrm{P}$ and SJF soils, and Freundlich relationships were used to evaluate the sorption behavior according to OECD guideline. Equilibrium status was reached after $2 \mathrm{~h}$ for both soils. Leptospermone was moderately adsorbed on the two soils. $K_{\mathrm{fa}}$-values were similar: 1.29 and 1.23 for $\mathrm{P}$ and SJF soils, respectively $\left(R^{2}>0.96\right) . K_{\mathrm{oc}}$-values, representing the adsorption of the pesticide normalized by soil organic carbon content, were slightly higher for $\mathrm{P}$ soil $\left(143.86 \mathrm{~mL} \mathrm{~g}^{-1}\right)$ than SJF soil (136.66 $\left.\mathrm{mL} \mathrm{g}^{-1}\right)$. All along the incubation period, the dissipation of the bioherbicide was monitored in D1 and D10 in $\mathrm{P}$ and SJF soils (Figure 1). Leptospermone was extracted with a recovery rate of 73 and $50 \%$ for $\mathrm{P}$ and SJF soils, respectively. In D1 microcosms, a lag phase of 2.5 and 8 days was observed for $\mathrm{P}$ and SJF soils, respectively. In contrast, no lag phase was observed in D10 microcosms for both soils. Leptospermone halflife $\left(\mathrm{DT}_{50}\right)$ in $\mathrm{P}$ soil estimated from dissipation kinetics was about 4 and 6 days in D1 and D10 microcosms, respectively. In contrast, in SJF soil leptospermone $\mathrm{DT}_{50}$ was slightly longer than those recorded in $\mathrm{P}$ soil, averaging 9 days, and was not depending on initial applied concentration. By the end of the incubation period, almost all the leptospermone was dissipated from D1 and D10 P soil while about $25 \%$ of leptospermone initially added remained in the D10 SJF soil. A rather low dissipation of leptospermone (5 to 20\%) was observed in sterilized soils, suggesting that dissipation was mainly governed by biotic processes.

\section{Impact of Leptospermone on the Composition of the Microbial Community}

The impact of leptospermone on the composition of the microbial community in the two soils was monitored by quantifying the abundance of the total bacterial community and 11 microbial groups. Total $16 \mathrm{~S}$ rRNA gene copy numbers ranged from $7.84 \times 10^{4}$ to $1.55 \times 10^{7}$ sequences per nanograms of DNA were extracted from soil microcosms. Although P and SJF soils had different physicochemical properties, the abundance of the total bacterial community did not differ significantly. No significant time or soil effects were observed on the total bacterial community. A multiple comparison test showed a significant impact of the treatment on the abundance of the total bacterial community at 4 days for $\mathrm{P}$ soil ( $p=0.03$, Kruskal-Wallis). For SJF soil, the abundance of bacterial community was fluctuating, however, D0 community did not significantly differ from D1 and D10 whatever the sampling time (data not shown).

The possible impact of leptospermone on the composition of the microbial community was further investigated by quantifying the abundances of eleven taxa ( $\alpha$-Proteobacteria, $\beta$ Proteobacteria, $\gamma$-Proteobacteria, Acidobacteria, Actinobacteria, Verrucomicrobia, Bacteroidetes, Firmicutes, Gemmatimonadetes, Planctomycetes, and Crenarchaeota). For each taxonomic group, qPCR results were expressed as percentage of total microbial community estimated by summing the abundances of all the phyla (Supplementary Figure 1). Before treatment, the microbial community of the two soils was dominated by two phyla (i.e., 
A

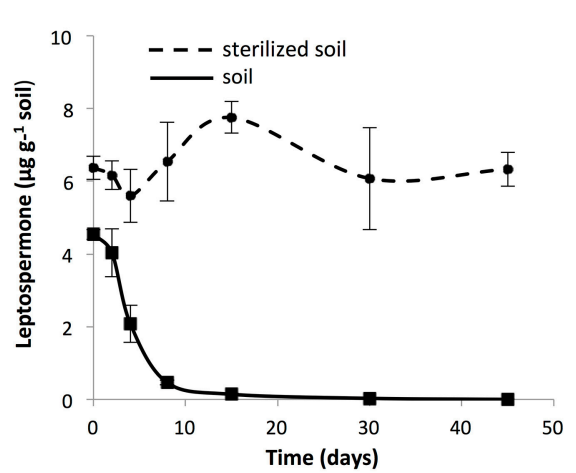

B

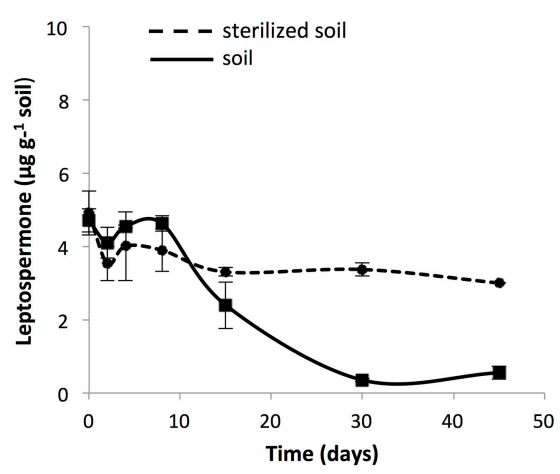

C

D10 (50 $\mu \mathrm{g} \mathrm{g}^{-1}$ per soil)

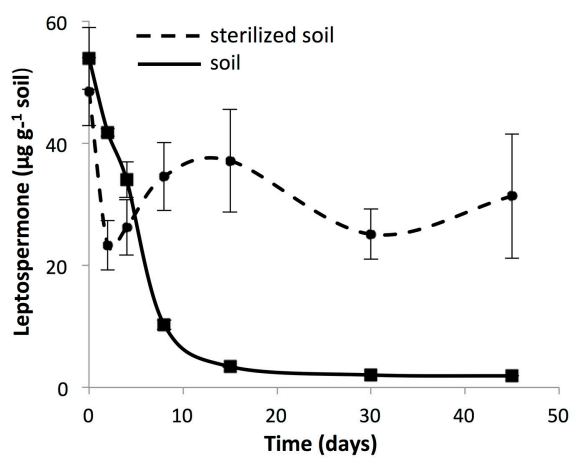

D

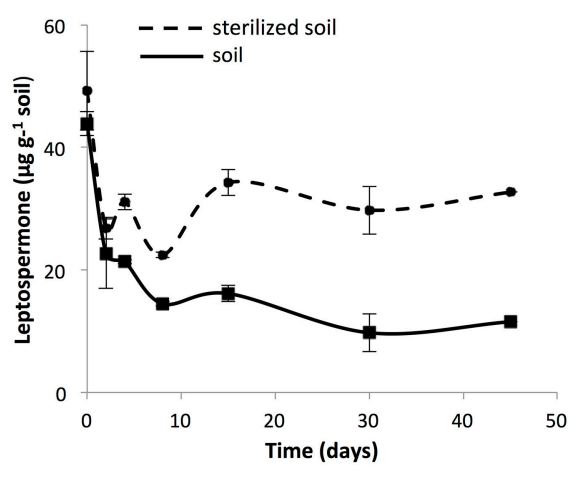

FIGURE 1 | Dissipation kinetics of $1 \times$ recommended rate leptospermone (D1; $5 \mu \mathrm{g} \mathrm{g}^{-1}$ ) in sterilized ( $(0)$ and unsterilized soils ( $\square$ ) from (A) P and (B) SJF, and 10x the recommended rate (D10; $\left.50 \mu \mathbf{g ~ g}^{-1}\right)$ in the soil from (C) P and (D) SJF. Standard deviations are indicated $(n=3)$.

Actinobacteria and Bacteroidetes) representing up to $70 \%$ of the total bacterial community. Leptospermone treatment modified significantly the abundances of $\alpha$-, $\beta$-, and $\gamma$-Proteobacteria, Acidobacteria, Actinobacteria, and Firmicutes $(p<0.001)$. The abundance of $\beta$-Proteobacteria increased in the presence of leptospermone at $0,2,4,8,15$, and 45 days in $\mathrm{P}$ soil, and at $4,8,15,30$, and 45 days in SJF soil $(p<0.05)$. Similarly, the abundance of $\gamma$-Proteobacteria was significantly increased at the higher leptospermone dose (D10) in P (2 days) and SJF (2, 4, 8,15 , and 30 days) soils. In contrast, the relative abundance of Acidobacteria was significantly decreased in $\mathrm{P}(0,2,4$, and 30 days) and SJF (8 days) treated soils $(p<0.05)$ as compared to respective D0. Similarly, the relative abundance of Firmicutes was considerably affected in P (2 and 4 days) and SJF (8 days) soils at the highest dose (D10). The same trend was observed for the relative abundance of Planctomycetes which was lower in D10 P (0 and 30 days) and D1 SJF (2, 4, 8, and 45 days) soils as compared to respective D0. The relative abundance of other phyla fluctuated over time without clear trend in response to leptospermone exposure.

\section{Impact of Leptospermone on Bacterial Diversity}

To further investigate the impact of leptospermone on the microbial community, the bacterial diversity was monitored by 454 pyrosequencing of $16 \mathrm{~S}$ rRNA amplicons obtained from $\mathrm{P}$ and
SJF soils exposed (D1 and D10) or not (D0) to leptospermone collected at 4 and 45 days. These points were chosen based on qPCR results (significantly impacted time points). Overall following de-multiplexing and removal of law-quality reads, 454pyrosequecing generated 189890 high-quality raw sequence reads of 16S rRNA sequences ranging from 250 and 310 bp in length (Sequence lengths (mean \pm std): $266.17 \pm 9.17$ ). These sequences were grouped into 4617 OTUs at 97\% nucleotide sequence identity threshold.

In agreement with $\mathrm{qPCR}$ results, $\alpha$-diversity estimated by a range of indices (Table 1) was time-dependent for all soils. In addition, similar diversity was recorded in both soils although they showed different physicochemical properties. For both soils, the Phylogenetic Diversity (PD) Whole Tree, the Chaol and the Shannon indices gave the same trend indicating that, at 4 days, the bacterial diversity significantly decreased in D1 an D10 microcosms ( $p=0.002, p=0.002$, and $p=0.001$, respectively). This decrease was accompanied by an increase in the dominance index in both soils $(p<0.05)$. Forty-five days after leptospermone application to the $\mathrm{P}$ soil, most of diversity indices estimated from D1 and D10 soils recovered the values measured in D0. In contrast, in SJF soil, for the highest application dose the decrease in the bacterial diversity (PD, Chaol and Shannon indices, $p<0.06$ ) and the increase in the dominance index were persisting. Good's estimator was comprised between 0.76 and 0.89 indicating a relatively good coverage for each sample. 
TABLE 1 | Richness and diversity indices of the bacterial community were calculated for P and SJF soil microcosms exposed to leptospermone applied at different concentrations (D0, D1, and D10) at 4 and 45 days.

\begin{tabular}{|c|c|c|c|c|c|c|}
\hline Soil and treatment & PD whole tree & Chao1 & Dominance & Simpson & Shannon & Good's coverage \\
\hline $\mathrm{P}$ d4 D0 & $59.36 \pm 1.53^{a}$ & $1222 \pm 72^{a}$ & $0.005 \pm 0.001^{a}$ & $0.995 \pm 0.001^{a}$ & $8.59 \pm 0.09^{a}$ & $0.80 \pm 0.009^{a}$ \\
\hline P d4 D1 & $40.25 \pm 5.91^{b}$ & $824 \pm 137^{b}$ & $0.097 \pm 0.070^{b}$ & $0.903 \pm 0.070^{b}$ & $6.27 \pm 1.04^{b}$ & $0.87 \pm 0.021^{b}$ \\
\hline P d4 D10 & $38.86 \pm 3.92^{b}$ & $849 \pm 103^{b}$ & $0.143 \pm 0.062^{b}$ & $0.857 \pm 0.062^{b}$ & $5.55 \pm 0.77^{c}$ & $0.87 \pm 0.017^{b}$ \\
\hline$P$ d45 D0 & $71.29 \pm 2.44^{a}$ & $1457 \pm 84^{a}$ & $0.003 \pm 0.000^{a}$ & $0.997 \pm 0.000^{a}$ & $9.02 \pm 0.12^{a}$ & $0.76 \pm 0.014^{a}$ \\
\hline P d45 D1 & $69.86 \pm 1.13^{a}$ & $1392 \pm 64^{a}$ & $0.004 \pm 0.000^{a}$ & $0.996 \pm 0.000^{b}$ & $8.86 \pm 0.06^{a}$ & $0.77 \pm 0.010^{a}$ \\
\hline P d45 D10 & $65.04 \pm 3.56^{a}$ & $1341 \pm 52^{a}$ & $0.006 \pm 0.001^{a}$ & $0.994 \pm 0.001^{b}$ & $8.57 \pm 0.17^{b}$ & $0.78 \pm 0.012^{a}$ \\
\hline SJF d4 DO & $62.68 \pm 0.83^{a}$ & $1379 \pm 25^{a}$ & $0.009 \pm 0.002^{a}$ & $0.991 \pm 0.002^{a}$ & $8.48 \pm 0.10^{a}$ & $0.77 \pm 0.001^{a}$ \\
\hline SJF d4 D1 & $48.52 \pm 0.31^{b}$ & $1100 \pm 58^{b}$ & $0.027 \pm 0.006^{b}$ & $0.973 \pm 0.006^{b}$ & $7.18 \pm 0.09^{b}$ & $0.83 \pm 0.006^{b}$ \\
\hline SJF d4 D10 & $37.31 \pm 2.13^{C}$ & $825 \pm 54^{C}$ & $0.038 \pm 0.007^{b}$ & $0.962 \pm 0.007^{c}$ & $6.49 \pm 0.21^{b}$ & $0.87 \pm 0.010^{b}$ \\
\hline SJF d45 D0 & $64.19 \pm 3.25^{a}$ & $1387 \pm 26^{a}$ & $0.009 \pm 0.002^{a}$ & $0.991 \pm 0.002^{a}$ & $8.56 \pm 0.11^{a}$ & $0.77 \pm 0.002^{a}$ \\
\hline SJF d45 D1 & $64.48 \pm 5.01^{a}$ & $1396 \pm 14^{a}$ & $0.012 \pm 0.004^{a}$ & $0.988 \pm 0.004^{b}$ & $8.48 \pm 0.22^{a}$ & $0.77 \pm 0.021^{a}$ \\
\hline SJF d45 D10 & $33.29 \pm 0.75^{b}$ & $679 \pm 44^{b}$ & $0.022 \pm 0.002^{b}$ & $0.978 \pm 0.002^{b}$ & $6.73 \pm 0.04^{b}$ & $0.89 \pm 0.005^{b}$ \\
\hline
\end{tabular}

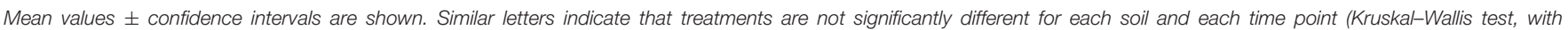
Conover's-test for post-hoc multiple comparisons, $P<0.05$ were considered as significant).

Whatever the soil considered, a dose effect was recorded showing that the bacterial diversity was inversely proportional to the dose applied (i.e., D1 $>$ D10, PD, Chaol and Shannon indices, Mann-Whitney $U, p<0.05)$.

The ecotoxicological impact of leptospermone on the bacterial diversity of $\mathrm{P}$ and SJF soils was evaluated using the $\beta$-diversity of 16S rRNA barcoding. The analysis of the Principal Coordinates Analyses (PCoA) representing the weighted Unifrac distances showed differences in the bacterial community composition between treatments (D0 vs. D1 and D10), soil type (P vs. SJF) and sampling time (d4 vs. d45) (PERMANOVA, $p=0.001$ ) (Figure 2). In addition, a good reproducibility between replicates of each treatment was observed regardless of the soil and the sampling time considered. The bacterial community of the $\mathrm{P}$ soil was discriminated from that of SJF along PCoA2 whatever the sampling time and treatment considered. For both soils, 4 days after the treatment, the composition of bacterial community of D1 and D10 soils significantly differed from their respective D0 along PCoA1 accounting for $48 \%$ of the variance observed. It is noteworthy that the effect was not dose-dependent (D1=D10) for $\mathrm{P}$ soil whereas a considerable dose effect was observed for SJF soil. Forty-five d after the treatment, the bacterial composition of $\mathrm{P}$ soil (D1 and D10) was not significantly different from D0 and was similar to that of D0 at 4 days of incubation. One the contrary, the recovery of the bacterial composition occurred only for the lowest dose of leptospermone applied (D0=D1) for SJF soil. The bacterial composition of D10 remains different in a similar manner to D1 and D10 after 4 days of exposure (i.e., $\left.\mathrm{D} 10_{\mathrm{d} 45} \neq \mathrm{D} 0_{\mathrm{d} 45}=\mathrm{D} 1_{\mathrm{d} 45}\right)$.

To further evaluate the ecotoxicological impact of leptospermone application on the composition of the bacterial community, the alignment of the obtained sequences together with known 16S rRNA sequences led to the identification of 33 phyla, 103 classes, 333 families, and 519 of bacterial genera. The phylogenetic tree drawn with iTOL using sequences obtained from P and SJF soils is presented in the Figure 3. The relative abundances of most important 250 OTUs gathered in 12 bacterial phyla ( $\alpha$-, $\beta$-, $\gamma$-, and $\delta$-Proteobacteria, Acidobaceteria, Actinobacteria, Verrumicrobiota, Nirospirare, Chhlorflexi, Bacteriodetes, Firmicutes, and Gemmatimonadetes) are shown. The analysis of the phylogenetic tree allowed the discrimination of $\mathrm{P}$ and SJF soils before treatment for several phyla (i.e., Bacteroidetes). It also revealed that for both soils the composition of bacterial community was deeply affected by the treatment as compared to D0. As an example, for both soils, the relative abundances of an important number of OTUs gathered to $\beta$-Proteobacteria were higher in D1 and D10 soils than in D0. On the contrary, the relative abundances of almost all OTUs gathered in Acidobacteria phylum were decreased in D1 and D10 soils as compared to D0. It is noteworthy that for a number of phyla (including $\beta$-Proteobacteria and Acidobacteria), changes in bacterial composition were proportional to the applied dose of leptospermone (D10>D1).

The relative abundances of the 33 phyla identified in $\mathrm{P}$ and SJF soils exposed (D1 and D10) or not (D0) to leptospermone for 4 and 45 days are presented in Figure 4. After 4 days of incubation, the bacterial community of both D0 soils was dominated by several bacterial classes including $\alpha$-Proteobacteria (P 21.6\%, SJF 21.3\%), $\beta$-Proteobacteria (P 12.4\%, SJF 15\%), $\gamma$ Proteobacteria (P 7.3\%, SJF 4.35\%), Bacteroidetes (P 7.58\%, SJF $10.32 \%)$, Acidobacteria (P 7.58\%, SJF 7.54\%), and Actinobacteria (P $4.05 \%$, SJF $8.49 \%$ ). For both leptospermone-treated soils, the abundance of $\beta$-Proteobacteria increased by 35 to $60 \%$ whereas the abundance of Acidobacteria and Bacteroidetes decreased by 0.91 to $1.65 \%$ and 2.0 to $6.5 \%$, respectively. Although the Chloroflexi represented only $3 \%$ of the overall bacterial community of the native soils, their abundance was reduced to $1 \%$ in the presence of the bioherbicide. Remarkably, at 4 days the abundances of Opitutales, Gaiellales, Acidimicrobiales, and Legionellales orders were lower in D10 than in D1 while the abundances of Pseudomonadales and Enterobacteriales orders were higher in D10 than in D1 (Mann-Whitney U, $p<0.05$ ). A time-dependent effect was observed in $\mathrm{P}$ soil 45 days after treatment. Abundances of bacterial groups (D1 and D10) were 


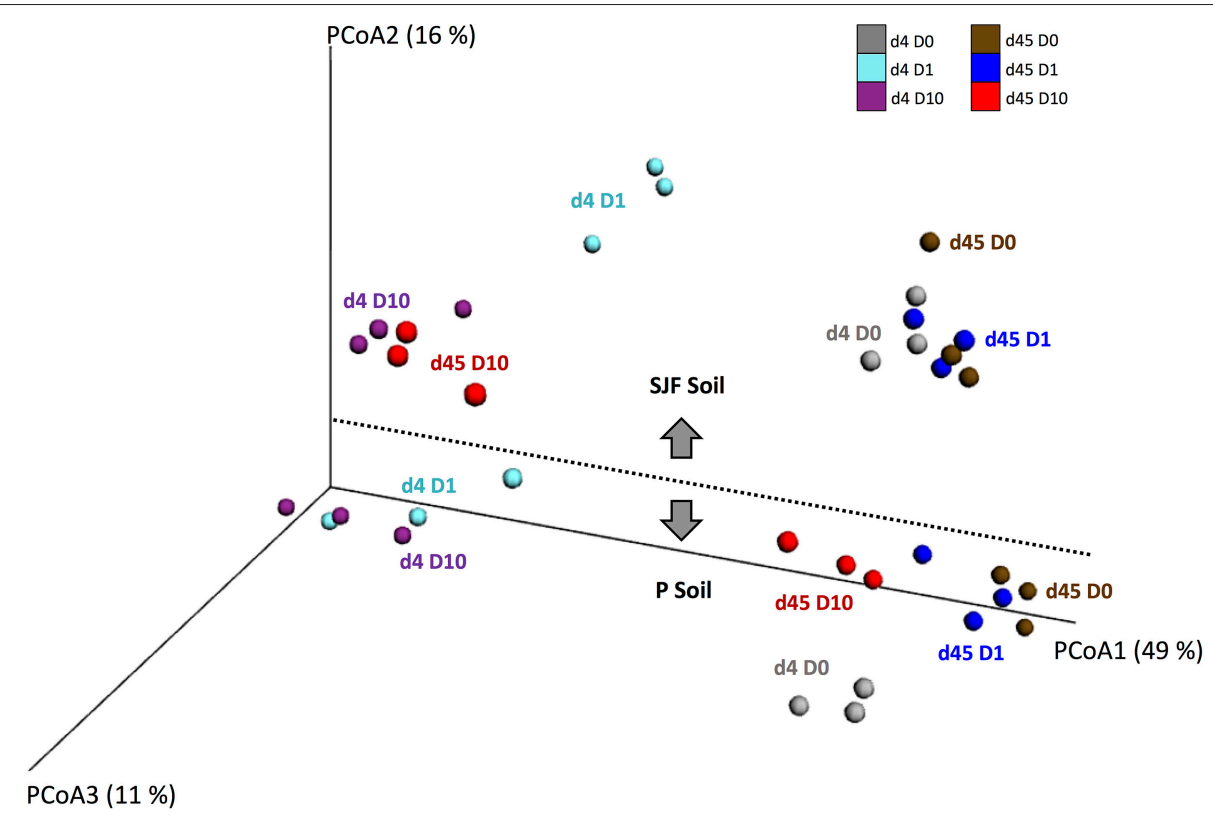

FIGURE 2 | UniFrac analysis of the effect of leptospermone applied at different concentrations (D0, D1, and D10) on the bacterial community composition of $\mathbf{P}$ and SJF soils at $\mathbf{4}$ and $\mathbf{4 5}$ days (d4, d45). The first three axes of the PCoA of the weighted UniFrac distance matrix of $16 \mathrm{~S}$ rRNA amplicon pyrosequencing are shown. The percent of variance explained by each axis is given. For both soils, treatments are as follows: at 4 days for D0, D1, and D10 (gray, cyan, and dark violet), and at 45 days for DO, D1, and D10 (brown, blue and red).

close to those of D0 and seemed to recover their initial state. In contrast, the composition of the bacterial community in D10 was different from D0 in SJF soil. Abundances of bacterial groups including Bacteroidetes and Verrumicrobiota were similar to D0 (45 days), whereas the abundances of $\alpha$-Proteobacteria and $\beta$-Proteobacteria were higher in D10 than D0 at that time frame. A closer look to $\alpha$-Proteobacteria group revealed an unexpected increase in Bradyrhizobiaceae in comparison to D0 (2.95 and $5.93 \%$ for D0 and D10, respectively at 45 days). The same trend was observed for Sphingomonadaceae (15.63 and $23.65 \%$ for D0 and D10, respectively at 45 days).

In order to understand the shifts highlighted by PCoA analysis, the 333 families identified from 454-pyrosequencing were further analyzed with the pamr package. The relative abundances of families like Opitutaceae, Chitinophagaceae, Bradyrhizobiaceae, and Solibacteraceae decreased after leptospermone treatment (4 days), while others such as Methylophilaceae, Pseudomonadaceae, Enterobacteriaceae, and Xanthomonadaceae increased at the same time (Supplementary Figure 2). At 45 days, relative abundances of several families (e.g., Burkholderiaceae and Geodermatophilaceae) almost recovered D0 levels in P soil, but not in SJF soil.

\section{DISCUSSION}

\section{Fate of Leptospermone in Soil}

As a first step, we monitored the dissipation of leptospermone in the two soils in order to characterize the scenario of exposure of microbial community. Abiotic (i.e., adsorption) and biotic (i.e., biodegradation) processes governing the dissipation of herbicide in soil were investigated. Adsorption isotherms revealed that leptospermone had similar $K_{\mathrm{fa}}, 1 / \mathrm{n}_{\mathrm{fa}}$ (close to 1 ) and $K_{\mathrm{oc}}$ indicating a similar and moderate adsorption capacity of leptospermone to $\mathrm{P}$ and SJF soils. It is noteworthy that adsorption of leptospermone observed in $\mathrm{P}$ soil $\left(K_{\mathrm{oc}}=143.86\right.$ $\left.\mathrm{mL} \mathrm{g}^{-1}\right)$ is similar to that of sulcotrione $\left(K_{\mathrm{oc}}=144 \mathrm{~mL}\right.$ $\left.\mathrm{g}^{-1}\right)$, a synthetic $\beta$-triketone herbicide, reported in an earlier study (Chaabane et al., 2005). It is not surprising to have similar adsorption behavior of leptospermone in both soils because they have almost identical soil pH (i.e., $\mathrm{P}$ pH 7.62 vs. SJF $\mathrm{pH} 8.1$ ) and organic carbon content (i.e., P $0.98 \%$ vs. SJF $0.9 \%$ ) which are two parameters known to influence adsorption of herbicides on soil (Dyson et al., 2002). Despite the moderate affinity of leptospermone for $\mathrm{P}$ and SJF soils, the bioherbicide dissipated rapidly from both soils with half-lives $\left(\mathrm{DT}_{50}\right)$ ranging from 4

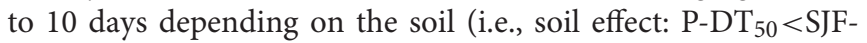
$\mathrm{DT}_{50}$ ) and on the treatment (i.e., dose effect: D1-DT ${ }_{50}<\mathrm{D} 10$ $\mathrm{DT}_{50}$ ). Leptospermone persisted longer in SJF than in $\mathrm{P}$ soil, particularly in D10 SJF soil where approximately $10 \mu \mathrm{g} \mathrm{g}^{-1}$ of leptospermone remained throughout the experiment. Since, the level of leptospermone did not decrease in sterilized soil microcosms its dissipation is dependent on biotic processes. This is consistent with previous reports on the biotic degradation of synthetic $\beta$-triketone herbicides (sulcotrione and mesotrione) in soil (Batisson et al., 2009; Crouzet et al., 2010; Calvayrac et al., 2012). Leptospermone $\mathrm{DT}_{50}$ was in the same range as sulcotrione and mesotrione, ranging from 8 to 65 days and 6 to 34 days, respectively (Dyson et al., 2002; Chaabane et al., 2008; Calvayrac et al., 2012). Based on the dissipation kinetics, we conclude that 


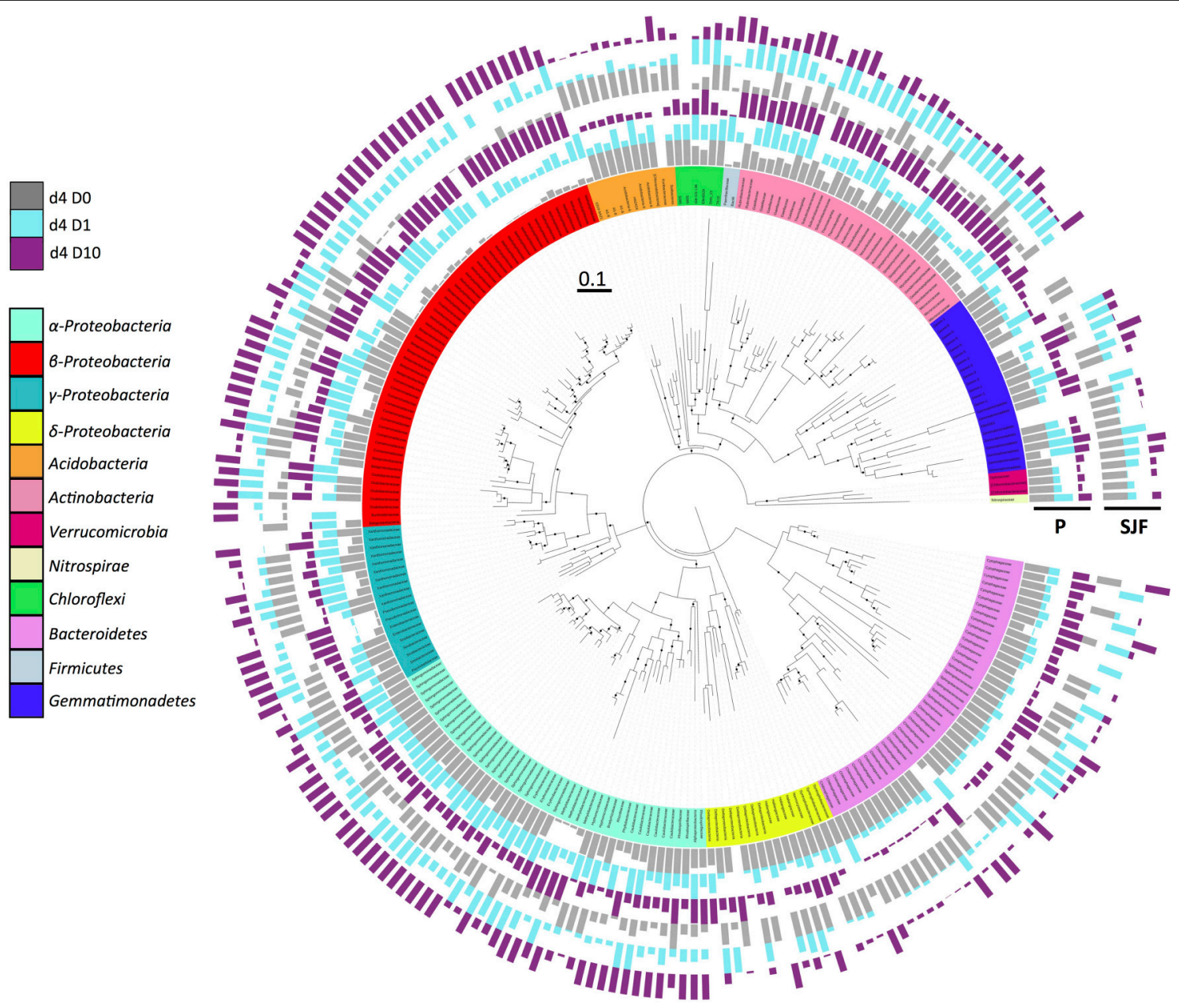

FIGURE 3 | Phylogenetic relationships and distribution of 16 S rRNA OTUs observed in P and SJF soils at 4 days (d4). The maximum likelihood phylogeny consists of representative nucleotide sequences for OTUs. Node confidence ( $n=1000$ bootstrap replicates) between 80 and $100 \%$ is shown by black dot. The affiliation of the represented OTUs to the main microbial groups (at phylum or class level) is indicated by different colors on the internal ring. Relative abundances of each OTU represented by bar plots are expressed as a proportion of the maximum abundance detected in each treatment, and indicated for P and SJF soils as follows (from inside to outside of the circle): gray, cyan, and dark violet for D0, D1, and D10, respectively.

the scenario of exposure of soil microorganisms to this natural $\beta$-triketone was differing between the two soils $(\mathrm{P}<\mathrm{SJF})$.

\section{Estimation of the Ecotoxicological Impact of Leptospermone}

The impact of leptospermone on the composition and on the diversity of the soil microbial community was assessed by qPCR targeting 11 microbial groups and 454 pyrosequencing, respectively. Actinobacteria and Bacteroidetes co-dominated the total bacterial community in both $\mathrm{P}$ and SJF soils as described in a range of other soils (Janssen, 2006; Acosta-Martinez et al., 2008; Wessen et al., 2010; Petric et al., 2011; Merlin et al., 2015). $16 \mathrm{~S}$ rRNA metabarcoding confirmed that these two groups as well as Proteobacteria and Acidobacteria phyla were dominating the bacterial community of both soils. This divergence between qPCR and 454 pyrosequencing could result from the degeneracy of the primers used to quantify the eleven microbial groups causing bias in the quantification as shown earlier by Bru et al. (2008). The abundances of several groups ( $\beta$ - and $\gamma$ Proteobacteria) increased in both soils, whereas the abundances of several others (Acidobacteria, Firmicutes, and Planctomyectes) decreased in leptospermone-treated soils. There was a transient loss in $\alpha$-diversity for both soils. Furthermore, $\beta$-diversity results confirmed significant changes in the composition of the bacterial community in both $\mathrm{P}$ and SJF soils at 4 days, which were recovered after 45 days of incubation in P (D1 and D10) and SJF (D1) soils, but not in D10 SJF soil. Altogether, leptospermone significantly reduced the bacterial diversity and altered the soil bacterial composition when less than $50 \%$ of the bioherbicide is dissipated. On the other hand, the bacterial diversity and composition of $\mathrm{P}$ and SJF soils recovered when leptospermone dissipated entirely from the $\mathrm{P}$ microcosm. However, this recovery was not achieved in the SJF soil treated with D10, where 10 $\mu \mathrm{g} \mathrm{g}^{-1}$ of leptospermone was still remained by the end of the experiment. 


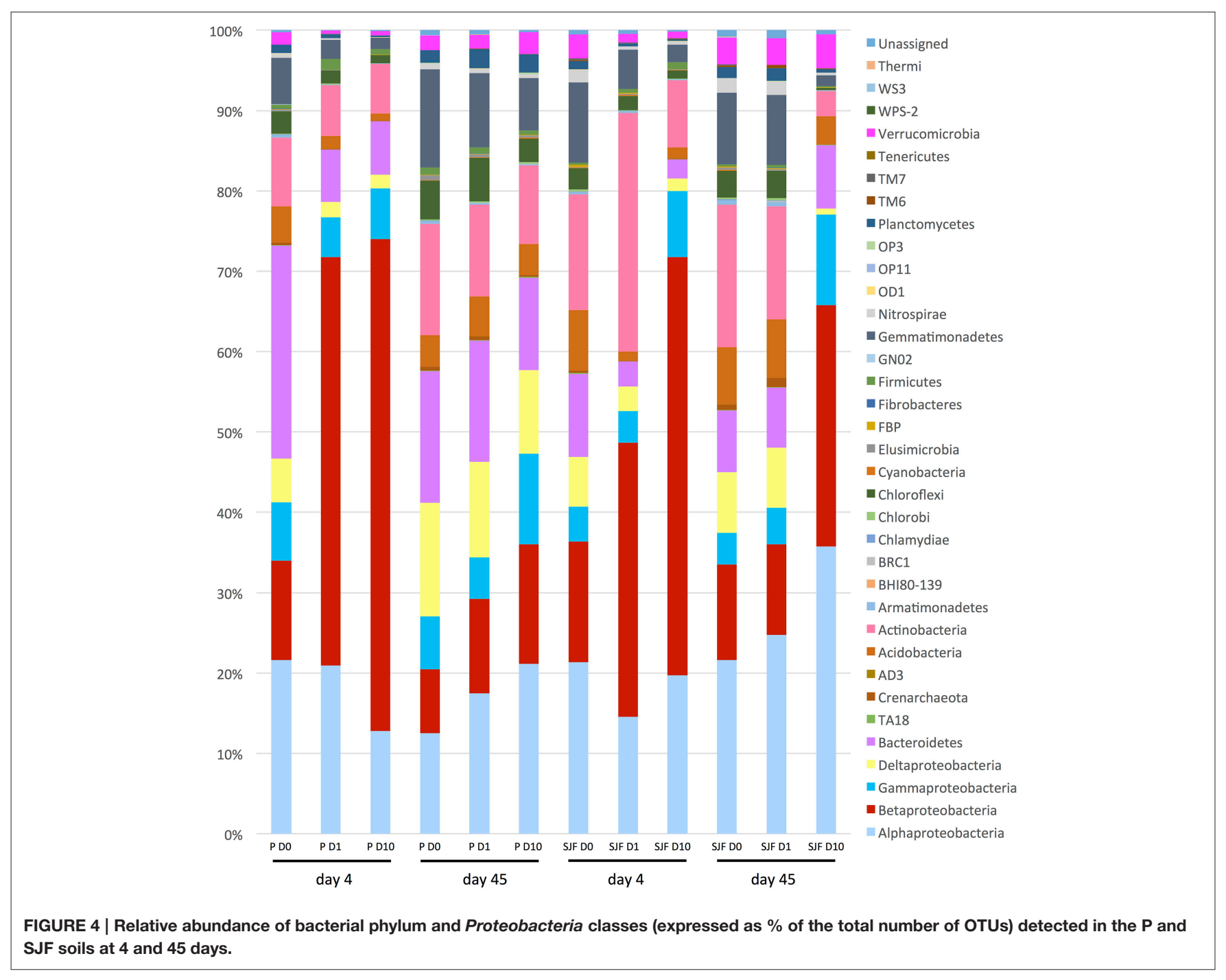

Although soil microorganisms are considered as NTO of $\beta$-triketone herbicides, most of them, express the $h p p d$ gene, coding for the HPPD enzyme targeted by these herbicides (Milcamps and de Bruijn, 1999; Moran, 2005). The observed loss in soil microbial diversity might be due to a disruption of bacterial tyrosine catabolism following the inhibition of HPPD by leptospermone. This may diminish the growth rate of sensitive populations (Milcamps and de Bruijn, 1999; Moran, 2005; Yang et al., 2007) while allowing leptospermone-tolerant microorganisms to expend. Changes in microbial diversity can also be caused by indirect toxic effect of leptospermone favoring the growth of saprophytic bacterial species feeding on dead leptospermone-sensitive microorganisms. The combination of direct and indirect ecotoxicological effects may explain changes caused by leptospermone on soil microbial diversity. While leptospermone caused a transient alteration of the composition and diversity of the soil microbial community, the biological significance of the ecotoxicological impact remains difficult to interpret in the absence of (i) normal operating range defining acceptable values for the measured parameters and (ii) an assessment of functional consequences of the changes observed.

The strong biotic control over the dissipation of leptospermone suggests that $\beta$-triketone-degrading populations can emerge in soils exposed to this chemistry. This hypothesis was tested by identifying bacterial groups with the most positive response in the presence of leptospermone. Within $\beta$ - and $\gamma$-Proteobacteria, the abundance of Methylophilales, Burkholderiales, Pseudomonadales, and Enterobacteriales increased significantly to leptospermone exposure. Relative groups belonging to these two orders are stress tolerant and degrade several contaminants including polycyclic aromatic hydrocarbons and various pesticides (Zhang et al., 2011, 2012; Calvayrac et al., 2012; Giri et al., 2013; Li et al., 2014; Fang et al., 2015). Since microbial degradation of pesticides is an adaptive response to cope with the stress imposed by xenobiotics (Crouzet et al., 2010; Olchanheski et al., 2014; Bardot et al., 2015), the emergence of degraders in the microbial community is a biomarker of exposure. Such responses in microbial community structure have already been described for 
other herbicides including mesotrione, glyphosate, s-triazine, and sulfonylurea (Busse et al., 2001; Ros et al., 2006; Weaver et al., 2007; Crouzet et al., 2010). However, the abundance of degrading populations remains rather low (i.e., between $10^{3}$ and $10^{4}$ cells per $g$ of soil) even in soil conditioned for rapid pesticide biodegradation (Piutti et al., 2003). Often emergence of degraders in microbial communities cannot be detected using tools targeting the overall microbial community because they might be hidden by dominant populations as demonstrated for chlordecone (Merlin et al., 2015). Therefore, the emergence of leptospermone degraders may make a negligible contribution to the overall microbial diversity of a soil. Therefore, the microbial biodegradation of leptospermone needs to be further studied using traditional enrichment culture techniques to better understand the environmental profile of leptospermone.

\section{CONCLUSION}

To our best knowledge this is the first study investigating the fate and the ecotoxicological impact of leptospermone on the composition and diversity of the soil microbial community. Leptospermone altered composition and diversity of soil microbial community despite of its relatively rapid rate of degradation. These changes were transient and when leptospermone was fully dissipated, the microbial community recovered its initial composition and diversity. However, the recovery cannot be reached in soil microcosms where leptospermone remained. Further work need to be done to test the ecotoxicological impact of natural $\beta$-triketone on a wider

\section{REFERENCES}

Acosta-Martinez, V., Dowd, S., Sun, Y., and Allen, V. (2008). Tag-encoded pyrosequencing analysis of bacterial diversity in a single soil type as affected by management and land use. Soil Biol. Biochem. 40, 2762-2770. doi: 10.1016/j.soilbio.2008.07.022

Bardot, C., Besse-Hoggan, P., Carles, L., Le Gall, M., Clary, G., Chafey, P., et al. (2015). How the edaphic Bacillus megaterium strain Mes11 adapts its metabolism to the herbicide mesotrione pressure. Environ. Pollut. 199, 198-208. doi: 10.1016/j.envpol.2015.01.029

Batisson, I., Crouzet, O., Besse-Hoggan, P., Sancelme, M., Mangot, J. F., Mallet, C., et al. (2009). Isolation and characterization of mesotrione-degrading Bacillus $\mathrm{sp}$ from soil. Environ. Pollut. 157, 1195-1201. doi: 10.1016/j.envpol.2008.12.009

Berry, D., Ben Mahfoudh, K., Wagner, M., and Loy, A. (2012). Barcoded primers used in multiplex amplicon pyrosequencing bias amplification. Appl. Environ. Microbiol. 78, 612-612. doi: 10.1128/AEM.07448-11

Bru, D., Martin-Laurent, F., and Philippot, L. (2008). Quantification of the detrimental effect of a single primer-template mismatch by real-time PCR using the $16 \mathrm{~S}$ rRNA gene as an example. Appl. Environ. Microbiol. 74, 1660-1663. doi: 10.1128/AEM.02403-07

Brussaard, L., Caron, P., Campbell, B., Lipper, L., Mainka, S., Rabbinge, R., et al. (2010). Reconciling biodiversity conservation and food security: scientific challenges for a new agriculture. Curr. Opin. Environ. Sustainability 2, 34-42. doi: 10.1016/j.cosust.2010.03.007

Busse, M. D., Ratcliff, A. W., Shestak, C. J., and Powers, R. F. (2001). Glyphosate toxicity and the effects of long-term vegetation control on soil microbial communities. Soil Biol. Biochem. 33, 1777-1789. doi: 10.1016/S00380717(01)00103-1

Cai, Z., Wang, J., Ma, J., Zhu, X., Cai, J., and Yang, G. (2015). Anaerobic degradation pathway of the novel chiral insecticide paichongding and its range of soil classes. In addition, it would be interesting to contrast the ecotoxicological impact of synthetic (sulcotrione and mesotrione) and natural $\beta$-triketones on soil microbial community.

\section{AUTHOR CONTRIBUTIONS}

SR, MD, LB, CC, CB, JC, FD, FM: Substantial contributions to the conception or design of the work; or the acquisition, analysis, or interpretation of data for the work; and drafting the work or revising it critically for important intellectual content; and final approval of the version to be published; and agreement to be accountable for all aspects of the work in ensuring that questions related to the accuracy or integrity of any part of the work are appropriately investigated and resolved.

\section{ACKNOWLEDGMENTS}

We would like to thank Aymé Spor (INRA Dijon) for his guidance for bioinformatics analyses and for helpful discussions. This work was supported by the French "Agence National de la Recherche” under TRICETOX project, number ANR-13-CESA0002 .

\section{SUPPLEMENTARY MATERIAL}

The Supplementary Material for this article can be found online at: http://journal.frontiersin.org/article/10.3389/fmicb. 2016.00775 impact on Bacterial communities in soils. J. Agric. Food Chem. 63, 7151-7160. doi: 10.1021/acs.jafc.5b02645

Calvayrac, C., Martin-Laurent, F., Faveaux, A., Picault, N., Panaud, O., Coste, C.M., et al. (2012). Isolation and characterisation of a bacterial strain degrading the herbicide sulcotrione from an agricultural soil. Pest Manag. Sci. 68, 340-347. doi: $10.1002 /$ ps.2263

Cantrell, C. L., Dayan, F. E., and Duke, S. O. (2012). Natural products as sources for new pesticides. J. Nat. Prod. 75, 1231-1242. doi: 10.1021/np300024u

Caporaso, J. G., Bittinger, K., Bushman, F. D., DeSantis, T. Z., Andersen, G. L., and Knight, R. (2010a). PyNAST: a flexible tool for aligning sequences to a template alignment. Bioinformatics 26, 266-267. doi: 10.1093/bioinformatics/b tp636

Caporaso, J. G., Kuczynski, J., Stombaugh, J., Bittinger, K., Bushman, F. D., Costello, E. K., et al. (2010b). QIIME allows analysis of highthroughput community sequencing data. Nat. Methods 7, 335-336. doi: 10.1038/nmeth.f.303

Caporaso, J. G., Lauber, C. L., Walters, W. A., Berg-Lyons, D., Lozupone, C. A., Turnbaugh, P. J., et al. (2011). Global patterns of 16 S rRNA diversity at a depth of millions of sequences per sample. Proc. Natl. Acad. Sci. U.S.A. 108, 4516-4522. doi: 10.1073/pnas.1000080107

Chaabane, H., Cooper, J. F., Azouzi, L., and Coste, C. M. (2005). Influence of soil properties on the adsorption-desorption of sulcotrione and its hydrolysis metabolites on various soils. J. Agric. Food Chem. 53, 4091-4095. doi: $10.1021 /$ jf040443c

Chaabane, H., Vulliet, E., Calvayrac, C., Coste, C. M., and Cooper, J.-F. (2008). Behaviour of sulcotrione and mesotrione in two soils. Pest Manag. Sci. 64, 86-93. doi: 10.1002/ps.1456

Cherrier, R., Perrin-Ganier, C., and Schiavon, M. (2004). Degradation of sulcotrione in a brown soil amended with various organic matters. Agronomie 24, 29-33. doi: 10.1051/agro:2003057 
Copping, L. G., and Menn, J. J. (2000). Biopesticides: a review of their action, applications and efficacy. Pest Manag. Sci. 56, 651-676. doi: 10.1002/15264998(200008)56:8<651::AID-PS201>3.0.CO;2-U

Crouzet, O., Batisson, I., Besse-Hoggan, P., Bonnemoy, F., Bardot, C., Poly, F., et al. (2010). Response of soil microbial communities to the herbicide mesotrione: a dose-effect microcosm approach. Soil Biol. Biochem. 42, 193-202. doi: 10.1016/j.soilbio.2009.10.016

Dayan, F. E., Cantrell, C., and Duke, S. O. (2009). Natural products in crop protection. Biorg. Med. Chem. 17, 4022-4034. doi: 10.1016/j.bmc.2009.01.046

Dayan, F. E., and Duke, S. O. (2014). Natural compounds as nextgeneration herbicides. Plant Physiol. 166, 1090-1105. doi: 10.1104/pp.114. 239061

Dayan, F. E., Duke, S. O., Sauldubois, A., Singh, N., McCurdy, C., and Cantrell, C. (2007). p-Hydroxyphenylpyruvate dioxygenase is a herbicidal target site for beta-triketones from Leptospermum scoparium. Phytochemistry 68, 2004-2014. doi: 10.1016/j.phytochem.2007.01.026

Dayan, F. E., Howell, J. L., Marais, J. P., Ferreira, D., and Koivunen, M. (2011). Manuka oil, a natural herbicide with preemergence activity. Weed Sci. 59, 464-469. doi: 10.1614/WS-D-11-00043.1

Dewhurst, I. C. (2001). Toxicological assessment of biological pesticides. Toxicol. Lett. 120, 67-72. doi: 10.1016/S0378-4274(01)00308-3

Dyson, J. S., Beulke, S., Brown, C. D., and Lane, M. C. G. (2002). Adsorption and degradation of the weak acid mesotrione in soil and environmental fate implications. J. Environ. Qual. 31, 613-618. doi: 10.2134/jeq2002.0613

Edgar, R. C. (2010). Search and clustering orders of magnitude faster than BLAST. Bioinformatics 26, 2460-2461. doi: 10.1093/bioinformatics/btq461

EFSA (2010). Scientific Opinion on the development of specific protection goal options for environmental risk assessment of pesticides, in particular in relation to the revision of the Guidance Documents on Aquatic and Terrestrial Ecotoxicology (SANCO/3268/2001 and SANCO/10329/2002). EFSA J. 8:1821. doi: $10.2903 /$ j.efsa.2010.1821

Fang, H., Lian, J., Wang, H., Cai, L., and Yu, Y. (2015). Exploring bacterial community structure and function associated with atrazine biodegradation in repeatedly treated soils. J. Hazard. Mater. 286, 457-465. doi: 10.1016/j.jhazmat.2015.01.006

Fierer, N., Jackson, J. A., Vilgalys, R., and Jackson, R. B. (2005). Assessment of soil microbial community structure by use of taxon-specific quantitative PCR assays. Appl. Environ. Microbiol. 71, 4117-4120. doi: 10.1128/AEM.71.7.41174120.2005

Giri, D. D., Shukla, P. N., Ritu, S., Kumar, A., and Pandey, K. D. (2013). Substrate utilization of stress tolerant methylotrophs isolated from revegetated heavy metal polluted coalmine spoil. World J. Microbiol. Biotechnol. 29, 635-643. doi: 10.1007/s11274-012-1219-7

Gopal, M., Gupta, A., Arunachalam, V., and Magu, S. P. (2007). Impact of azadirachtin, an insecticidal allelochemical from neem on soil microflora, enzyme and respiratory activities. Bioresour. Technol. 98, 3154-3158. doi: 10.1016/j.biortech.2006.10.010

Gray, R., Rusay, R., and Tseng, C. (1980). 1-Hydroxy-2-(alkylketo)- 4,4,6,6Tetramethyl Cyclohexen-3,5-Dione Herbicides. Westport, CT: US Patent, patent application.

Gupta, S., Gupta, R., and Sharma, S. (2013). Impact of chemical- and biopesticides on bacterial diversity in rhizosphere of Vigna radiata. Ecotoxicology 22, 1479-1489. doi: 10.1007/s10646-013-1134-1

Hellyer, R. O. (1968). The occurrence of $\beta$-triketones in the steam-volatile oils of some myrtaceous Australian plants. Austr. J. Chem. 21, 2825-2828. doi: 10.1071/CH9682825

Henry, S., Bru, D., Stres, B., Hallet, S., and Philippot, L. (2006). Quantitative detection of the nosZ gene, encoding nitrous oxide reductase, and comparison of the abundances of $16 \mathrm{~S}$ rRNA, narG, nirK, and nosZ genes in soils. Appl. Environ. Microbiol. 72, 5181-5189. doi: 10.1128/AEM. 00231-06

Janssen, P. H. (2006). Identifying the dominant soil bacterial taxa in libraries of 16S rRNA and 16S rRNA genes. Appl. Environ. Microbiol. 72, 1719-1728. doi: 10.1128/AEM.72.3.1719-1728.2006

Jeong, E. Y., Jeon, J.-H., Kim, H. W., Kim, M. G., and Lee, H. S. (2009a). Antimicrobial activity of leptospermone and its derivatives against human intestinal bacteria. Food Chem. 115, 1401-1404. doi: 10.1016/j.foodchem.2009.01.086
Jeong, E. Y., Kim, M. G., and Lee, H. S. (2009b). Acaricidal activity of triketone analogues derived from Leptospermum scoparium oil against house-dust and stored-food mites. Pest Manag. Sci. 65, 327-331. doi: 10.1002/ps.1684

Lee, C. M., Yeo, Y. S., Lee, J. H., Kim, S. J., Kim, J. B., Han, N. S., et al. (2008). Identification of a novel 4-hydroxyphenylpyruvate dioxygenase from the soil metagenome. Biochem. Biophys. Res. Commun. 370, 322-326. doi: 10.1016/j.bbrc.2008.03.102

Letunic, I., and Bork, P. (2007). Interactive Tree Of Life v2: online annotation and display of phylogenetic trees made easy. Nucleic Acids Res. 39, W475-W478. doi: 10.1093/nar/gkr201

Li, R., Khafipour, E., Krause, D. O., Entz, M. H., de Kievit, T. R., and Fernando, W. G. D. (2014). Pyrosequencing reveals the influence of organic and conventional farming systems on bacterial communities. PLoS ONE 7:e51897. doi: 10.1371/journal.pone.0051897

Liu, Z., Lozupone, C., Hamady, M., Bushman, F. D., and Knight, R. (2007). Short pyrosequencing reads suffice for accurate microbial community analysis. Nucleic Acids Res. 35, e120. doi: 10.1093/nar/gkm541

Margni, M., Rossier, D., Crettaz, P., and Jolliet, O. (2002). Life cycle impact assessment of pesticides on human health and ecosystems. Agric. Ecosyst. Environ. 93, 379-392. doi: 10.1016/S0167-8809(01)00336-X

Martin-Laurent, F., Kandeler, E., Petric, I., Djuric, S., and Karpouzas, D. G. (2013). ECOFUN-MICROBIODIV: an FP7 European project for developing and evaluating innovative tools for assessing the impact of pesticides on soil functional microbial diversity-towards new pesticide registration regulation? Environ. Sci Pollut. Res. Int. 20, 1203-1205. doi: 10.1007/s11356-012-1368-0

Martin-Laurent, F., Philippot, L., Hallet, S., Chaussod, R., Germon, J. C., Soulas, G., et al. (2001). DNA extraction from soils: old bias for new microbial diversity analysis methods. Appl. Environ. Microbiol. 67, 2354-2359. doi: 10.1128/AEM.67.5.2354-2359.2001

Meazza, G., Scheffler, B. E., Tellez, M. R., Rimando, A. M., Romagni, J. G., Duke, S. O., et al. (2002). The inhibitory activity of natural products on plant p-hydroxyphenylpyruvate dioxygenase. Phytochemistry 60, 281-288. doi: 10.1016/S0031-9422(02)00121-8

Merlin, C., Devers, M., Béguet, J., Boggio, B., Rouard, N., and Martin-Laurent, F. (2015). Evaluation of the ecotoxicological impact of the organochlorine chlordecone on soil microbial community structure, abundance, and function. Environ. Sci. Pollut. Res. 23, 4185-4198. doi 10.1007/s11356-015-4758-2

Milcamps, A., and de Bruijn, F. J. (1999). Identification of a novel nutrientdeprivation-induced Sinorhizobium meliloti gene (hmgA) involved in the degradation of tyrosine. Microbiology 145, 935-947. doi: 10.1099/13500872145-4-935

Mitchell, G., Bartlett, D. W., Fraser, T. E. M., Hawkes, T. R., Holt, D. C., Townson, J. K., et al. (2001). Mesotrione: a new selective herbicide for use in maize. Pest Manag. Sci. 57, 120-128. doi: 10.1002/1526-4998(200102)57:2<120::AIDPS254>3.0.CO;2-E

Moran, G. R. (2005). 4-Hydroxyphenylpyruvate dioxygenase. Arch. Biochem. Biophys. 433, 117-128. doi: 10.1016/j.abb.2004.08.015

Muhling, M., Woolven-Allen, J., Murrell, J. C., and Joint, I. (2008). Improved group-specific PCR primers for denaturing gradient gel electrophoresis analysis of the genetic diversity of complex microbial communities. ISME J. 2, 379-392. doi: 10.1038/ismej.2007.97

Muyzer, G., de Waal, E. C., and Uitterlinden, A. G. (1993). Profiling of complex microbial populations by denaturing gradient gel electrophoresis analysis of polymerase chain reaction-amplified genes coding for 16S rRNA. Appl. Environ. Microbiol. 59, 695-700.

Nannipieri, P., Ascher, J., Ceccherini, M. T., Landi, L., Pietramellara, G., and Renella, G. (2003). Microbial diversity and soil functions. Eur. J. Soil Sci. 54, 655-670. doi: 10.1046/j.1351-0754.2003.0556.x

Ochsenreiter, T., Selezi, D., Quaiser, A., Bonch-Osmolovskaya, L., and Schleper, C. (2003). Diversity and abundance of Crenarchaeota in terrestrial habitats studied by $16 \mathrm{~S}$ RNA surveys and real time PCR. Environ. Microbiol. 5, 787-797. doi: 10.1046/j.1462-2920.2003.00476.x

OECD (2000). Guidelines for the Testing of Chemicals; Adsorption-Desorption using a Batch Equilibrium Method. Paris: OECD Test Guideline 106. doi: 10.1787/9789264069602-en

Oksanen, J., Blanchet, F., Kindt, R., Legendre, P., O’Hara, R., Simpson, G., et al. (2011). Vegan: Community Ecology Package. Version 1.17-11. Available online at: http://vegan.r-forge.r-project.org/ 
Olchanheski, L. R., Dourado, M. N., Beltrame, F. L., Zielinski, A. A. F., Demiate, I. M., Pileggi, S. A. V., et al. (2014). Mechanisms of tolerance and high degradation capacity of the herbicide mesotrione by Escherichia coli strain DH5-alpha. PLoS ONE 9:e99960. doi: 10.1371/journal.pone.0099960

Owens, D. K., Nanayakkara, D. N. P., and Dayan, F. E. (2013). In planta mechanism of action of leptospermone: impact of its physico-chemical properties on uptake, translocation, and metabolism. J. Chem. Ecol. 39, 262-270. doi: 10.1007/s10886-013-0237-8

Petric, I., Bru, D., Udikovic-Kolic, N., Hrsak, D., Philippot, L., and Martin-Laurent, F. (2011). Evidence for shifts in the structure and abundance of the microbial community in a long-term PCB-contaminated soil under bioremediation. J. Hazard. Mater. 195, 254-260. doi: 10.1016/j.jhazmat.2011.08.036

Philippot, L., Bru, D., Saby, N. P. A., Cuhel, J., Arrouays, D., Simek, M., et al. (2009). Spatial patterns of bacterial taxa in nature reflect ecological traits of deep branches of the 16S rRNA bacterial tree. Environ. Microbiol. 11, 3096-3104. doi: 10.1111/j.1462-2920.2009.02014.x

Philippot, L., Ritz, K., Pandard, P., Hallin, S., and Martin-Laurent, F. (2012). Standardisation of methods in soil microbiology: progress and challenges. FEMS Microbiol. Ecol. 82, 1-10. doi: 10.1111/j.1574-6941.2012.01436.x

Piutti, S., Semon, E., Landry, D., Hartmann, A., Dousset, S., Lichtfouse, E., et al. (2003). Isolation and characterisation of Nocardioides sp SP12, an atrazinedegrading bacterial strain possessing the gene trzN from bulk- and maize rhizosphere soil. FEMS Microbiol. Lett. 221, 111-117. doi: 10.1016/S03781097(03)00168-X

Polyrakis, I. (2009). “Environmental pollution from pesticides," in Predictive Modeling and Risk Assessment, ed R. Costa and K. Kristbergsson (Heidelberg: Springer Science+Business Media), 201-224.

Price, M. N., Dehal, P. S., and Arkin, A. P. (2010). FastTree 2-Approximately maximum-likelihood trees for large alignments. PLoS ONE 5:e9490. doi: 10.1371/journal.pone.0009490

Ros, M., Goberna, M., Moreno, J. L., Hernandez, T., Garcia, C., Insam, H., et al. (2006). Molecular and physiological Bacterial diversity of a semi-arid soil contaminated with different levels of formulated atrazine. Appl. Soil Ecol. 34, 93-102. doi: 10.1016/j.apsoil.2006.03.010

Schulz, A., Ort, O., Beyer, P., and Kleinig, H. (1993). SC-0051, a 2-benzoylcyclohexane-1,3-dione bleaching herbicide, is a potent inhibitor of the enzyme p-hydroxyphenylpyruvate dioxygenase. FEBS Lett. 318, 162-166. doi: 10.1016/0014-5793(93)80013-K

Science for Environment Policy (2015). Ecosystem Services and the Environment. In-Depth Report 11 Produced For The European Commission, Bristol: DG Environment by the Science Communication Unit. Available online at: http://ec.europa.eu/science-environment-policy

Seiber, J. N., Coats, J., Duke, S. O., and Gross, A. D. (2014). biopesticides: state of the art and future opportunities. J. Agric. Food Chem. 62, 11613-11619. doi: $10.1021 /$ jf504252n

Singh, S., Gupta, R., Kumari, M., and Sharma, S. (2015a). Nontarget effects of chemical pesticides and biological pesticide on rhizospheric microbial community structure and function in Vigna radiata. Environ. Sci. Pollut. Res. 22, 11290-11300. doi: 10.1007/s11356-015-4341-x

Singh, S., Gupta, R., and Sharma, S. (2015b). Effects of chemical and biological pesticides on plant growth parameters and rhizospheric bacterial community structure in Vigna radiata. J. Hazard. Mater. 291, 102-110. doi: 10.1016/j.jhazmat.2015.02.053

Tibshirani, R., Hastie, T., Narasimhan, B., and Chu, G. (2002). Diagnosis of multiple cancer types by shrunken centroids of gene expression. Proc. Natl. Acad. Sci. U.S.A. 99, 6567-6572. doi: 10.1073/pnas.082099299

Trivella, A., Stawinoga, M., Dayan, F. E., Cantrell, C. L., Mazellier, P., and Richard, C. (2015). Photolysis of natural beta-triketonic herbicides in water. Water Res. 78, 28-36. doi: 10.1016/j.watres.2015.03.026

Turner, S., Pryer, K. M., Miao, V. P. W., and Palmer, J. D. (1999). Investigating deep phylogenetic relationships among cyanobacteria and plastids by small submit rRNA sequence analysis. J. Eukaryot. Microbiol. 46, 327-338. doi: 10.1111/j.1550-7408.1999.tb04612.x

Wang, Z. G., Hu, Y. L., Xu, W. H., Liu, S., Hu, Y., and Zhang, Y. (2015). Impacts of dimethyl phthalate on the bacterial community and functions in black soils. Front. Microbiol. 6:405. doi: 10.3389/fmicb.2015.00405

Weaver, M. A., Krutz, L. J., Zablotowicz, R. M., and Reddy, K. N. (2007). Effects of glyphosate on soil microbial communities and its Mississippi soil. Pest Manag. Sci. 63, 388-393. doi: 10.1002/ps.1351

Wessen, E., Hallin, S., and Philippot, L. (2010). Differential responses of bacterial and archaeal groups at high taxonomical ranks to soil management. Soil Biol. Biochem. 42, 1759-1765. doi: 10.1016/j.soilbio.2010.06.013

Whitman, W. B., Coleman, D. C., and Wiebe, W. J. (1998). Prokaryotes: the unseen majority. Proc. Natl. Acad. Sci. U.S.A. 95, 6578-6583. doi: 10.1073/pnas.95.12.6578

Wilson, J. S., and Foy, C. L. (1992). Influence of various soil properties on the adsorption and desorption of ICIA-0051 in 5 soils. Weed Technol. 6, 583-586.

Yang, H., Wang, L., Xie, Z., Tian, Y., Liu, G., and Tan, H. (2007). The tyrosine degradation gene hppD is transcriptionally activated by HpdA and HpdR in Streptomyces coelicolor, while hpdA is negatively autoregulated and repressed repressed by HpdR. Mol. Microbiol. 65, 1064-1077. doi: 10.1111/j.13652958.2007.05848.x

Zhang, S. Y., Wang, Q. F., Wan, R., and Xie, S. G. (2011). Changes in bacterial community of anthracene bioremediation in municipal solid waste composting soil. J. Zhejiang Univ. Sci. B 12, 760-768. doi: 10.1631/jzus.B10 00440

Zhang, S. Y., Wang, Q. F., and Xie, S. G. (2012). Bacterial and archaeal community structures in phenanthrene amended aquifer sediment microcosms under toxic and anoxic conditions. Int. J. Environ. Res. 6, 1077-1088. Retrieved from: https://ijer.ut.ac.ir/article_578_b5d259943c90865d3a49f380d907f9c5.pdf

Conflict of Interest Statement: The authors declare that the research was conducted in the absence of any commercial or financial relationships that could be construed as a potential conflict of interest.

Copyright (c) 2016 Romdhane, Devers-Lamrani, Barthelmebs, Calvayrac, Bertrand, Cooper, Dayan and Martin-Laurent. This is an open-access article distributed under the terms of the Creative Commons Attribution License (CC BY). The use, distribution or reproduction in other forums is permitted, provided the original author(s) or licensor are credited and that the original publication in this journal is cited, in accordance with accepted academic practice. No use, distribution or reproduction is permitted which does not comply with these terms. 